\title{
Pre-hospital treatment of STEMI patients \\ A scientific statement of the Working Group Acute Cardiac Care \\ of the European Society of Cardiology
}

Marco Tubaro ${ }^{1}$, Nicolas Danchin ${ }^{2}$, Patrick Goldstein ${ }^{3}$, Gerasimos Filippatos ${ }^{4}$, Yonathan Hasin ${ }^{5}$, Magda Heras $^{6}$, Petr Jansky ${ }^{7}$, Tone Norekval ${ }^{8}$, Eva Swahn ${ }^{9}$, Kristian Thygesen ${ }^{10}$, Christiaan Vrints ${ }^{11}$, Doron Zahger $^{12}$, Hans-Richard Arntz ${ }^{13}$, Abdelouahab Bellou ${ }^{14}$, Jean E. de la Coussaye ${ }^{15}$, Leonardo De Luca ${ }^{16}$, Kurt Huber $^{17}$, Yves Lambert ${ }^{18}$, Maddalena Lettino ${ }^{19}$, Bertil Lindahl ${ }^{20}$, Scott McLean ${ }^{21}$, Lutz Nibbe ${ }^{22}$, W. Frank Peacock $^{23}$, Susanna Price ${ }^{24}$, Tom Quinn ${ }^{25}$, Christian Spaulding ${ }^{26}$, Gabriel Tatu-Chitoiu ${ }^{27}$, Frans Van de Werf $^{28}$.

1 ICCU, Cardiovascular Department, San Filippo Neri Hospital, Rome (IT)

2 Department of Cardiology, Hôpital Europeen Georges Pompidou, Paris (FR)

3 ED and SAMU, Lille 2 University Hospital, Lille (FR)

4 Department of Cardiology, Athens University, Hospital Attikon, Athens (GR)

5 Cardiovascular Institute, Baruch Padeh Medical Center, Poria (IL)

6 Thorax Institute, Hospital Clinic, Barcelona (SP)

7 Department of Cardiovascular Surgery, University Hospital Motol, Prague (CZ)

8 Department of Heart Disease, Haukeland University Hospital, Bergen (NO)

9 ICCU, Division of Cardiovascular Medicine, Dept. Medical and Health Sciences, University Hospital, Linkoping (SE)

10 Department of Medicine and Cardiology, Aarhus University Hospital (DK)

11 Department of Cardiology, Antwerp University Hospital, Antwerp (BE)

12 Intensive Cardiac Heart Unit, Cardiology Department, Soroka University Medical Center, Beer Sheva (IL)

13 Med. Clinic, Department of Cardiopulmonology, Charitè, Campus Benjamin Franklin, Berlin (GE)

14 Emergency Department, University Hospital Rennes (FR)

15 Division of Anaesthesiology, Intensive Care, Pain and Emergency, SAMU 30, University Hospital, Nimes (FR)

16 Department of Cardiovascular Sciences, European Hospital, Rome (IT)

17 Department of Cardiology and Emergency Medicine, Wilhelminenhospital, Vienna (AT)

18 SAMU 78 and Mobile Intensive Care Unit, Centre Hospitalier de Versailles (FR)

19 ICCU, Cardiovascular Department, Fondazione IRCCS Policlinico S. Matteo Hospital, Pavia (IT)

20 Department of Medical Sciences, Cardiology and Uppsala Clinical Research Center, University of Uppsala (SE)

21 Barts and The London, London (UK)

22 Department of Nephrology and Intensive Care Medicine, Charitè, Campus Virchow-Klinikum (GE)

23 Emergency Medicine Institute, The Cleveland Clinic, Cleveland (USA)

24 Adult Intensive Care Unit, Royal Brompton Hospital, London (UK)

25 Faculty of Health and Medical Sciences, University of Surrey, Guildford (UK)

26 Department of Cardiology, Cochin Hospital, Assistance Publique, Hôpitaux de Paris, Paris Descartes University and INSERM U 970, Paris (FR)

27 Clinica de Medicina Interna si Cardiologie, Spitalul de Urgenta "Floreasca", Bucharest (RO)

28 Department of Cardiovascular Medicine, University Hospitals Leuven (BE)

corresponding author: Marco Tubaro, MD FESC, via Carlo Dossi 15, 00137 Roma (Italy)

tel/fax +39.06.86800907, e-mail: m.tubaro@alice,it

key-words: ST elevation myocardial infarction - acute coronary syndromes - acute cardiac care -

pre-hospital - emergency medical service - networks 


\section{Introduction}

Optimal treatment for ST-elevation myocardial infarction (STEMI) is based on a reperfusion strategy employing either primary percutaneous coronary intervention (PPCI) or thrombolytic therapy (TT). A sizable proportion of STEMI patients are not reperfused, time delays are frequently unacceptable ${ }^{1}$ and very few patients receive all the guideline-recommended therapies in a timely manner. Decision-making in the pre-hospital setting is pivotal for optimal STEMI care, and delays in therapy cannot later be compensated. Thus, the empowerment of paramedical staff is key to successful pre-hospital STEMI management. This requires the implementation of systems of care (STEMI networks), in which the Emergency Medical Service (EMS), non-PCI-capable hospitals, and hospitals with PCI facilities cooperate closely in order to reduce the total ischaemic time, increase the number of patients receiving reperfusion therapy, and to reduce heart failure and mortality ${ }^{2}$.

\section{Delays}

The total ischaemic time (Figure 1) is often unacceptably long with only 11-15\% patients treated within the recommended time intervals. ${ }^{3}$

Patient delay. An early first call to the EMS is desirable as rapid diagnosis and treatment at the scene has been shown to save lives and prevent complications. The patient's decision time (PDT) has historically remained constant at between 1-3 hours. Patients with longer PDTs tend to be older, female and diabetic, with atypical symptoms. There is significant variation in the use of EMS in STEMI (28-82\% patients) and in the PDTs (81-174 mins) throughout Europe. While several public initiatives have been successful in shortening PDTs, such campaigns have only a temporary impact.

An integral part of the EMS is triage by the emergency medical dispatcher. First medical contact is defined as the time at which STEMI diagnosis is made using ECG, irrespective of the setting.

Pre-hospital organisation. Not all patients referred for PPCI receive optimal percutaneous reperfusion (i.e. PCI performed in a timely manner by an experienced team), and even in urban locations a minority still require pre-hospital thrombolysis $(\mathrm{PH}-\mathrm{T})^{4}$. Geographical considerations and distribution of PPCI centres are two factors that contribute to the variability in European rates (5-92\%). ${ }^{5}$ The best evidence for reperfusion 
strategies is based on in-hospital STEMI studies, and more high-quality research on the pre-hospital environment is needed. The key to diagnosis is the pre-hospital electrocardiogram (PH-ECG) ${ }^{6}$, interpreted on site and/or transmitted for interpretation

\section{Pre-hospital ECG}

The use of the PH-ECG is widespread in some countries and has been shown to reduce the time to reperfusion and mortality in patients with STEMI. Trained paramedics can identify STEMI with a good sensitivity and specificity, with multiple studies demonstrating that PH-ECGs decrease door-to-needle (D2N) and door-to-balloon (D2B) times. ${ }^{7}$

\section{Reperfusion strategies}

PH-T significantly reduces reperfusion time when compared with awaiting $\mathrm{IH}-\mathrm{T}$, increases the odds of aborted MI and improves outcome ${ }^{8}$. The advantages of integrating TT and PCI have been demonstrated in several studies, and in order to facilitate this, networks for STEMI management should be developed on a national and/or regional level, with continued measurement of outcome and quality metrics.

\section{Registries and STEMI networks: organization and outcome in practice}

STEMI mortality reported in registries is higher than in randomized clinical trials (RCTs). As the results of RCTs may only be applicable to $50 \%$ of patients in clinical practice, registry data may provide additional information, including the challenges in implementing RCT-derived recommendations. As shown from registry data, an increase in the PPCI-related delay (D2B minus D2N time) is associated with higher mortality rates. The time point at which PPCI loses its survival advantage over fibrinolysis varies considerably between subgroups, from $<1$ hour to 3 hours $^{9}$. Registry data also show that field transfer is faster than inter-hospital transfer, resulting in more patients achieving a D2B time $\leq 90$ mins. The main findings ${ }^{10-13}$ of selected European registries on pre-hospital STEMI care are shown in Table 1.

\section{Pre-hospital adjuvant therapies}

Several recommendations have been made to attempt to standardise care and reduce major adverse cardiac 
events (MACE) and mortality in pre-hospital STEMI management (Table 2). Some drugs effective for inhospital STEMI treatment are not indicated (GP IIb/IIIa inhibitors) or are lacking data in the pre-hospital setting (prasugrel, bivalirudin).

\section{Pre-hospital management of STEMI complications}

Timely and appropriate pre-hospital management can stabilise the patient, enabling safe transportation to the most appropriate hospital for more definite treatment.

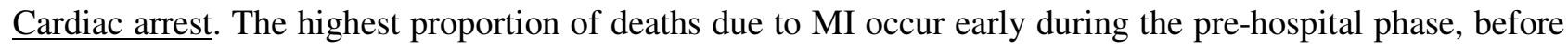
any medical support is at hand. The commonest cause is ventricular fibrillation, induced by ischaemia and reperfusion. In patients with no return of spontaneous circulation (ROSC), TT does not improve survival ${ }^{14}$. PPCI is an alternative for reperfusion in survivors of out-of-hospital cardiac arrest, and may be an independent predictor of survival. ${ }^{15}$

Therapeutic hypothermia should be part of the standardised treatment strategy for comatose survivors of cardiac arrest.

Cardiac arrhythmias. Arrhythmias are associated with increased mortality in acute coronary syndromes (ACS). Basic and advanced life-support algorithms and defibrillation/cardioversion should be applied where indicated. Beta-blockers and amiodarone may be considered in case of ventricular tachyarrhythmias; alternative drugs are class $1 \mathrm{~A} / 1 \mathrm{~B}$ antiarrhythmics.

Acute bradycardia due to STEMI. Complete heart block during STEMI is associated with a high mortality rate. Severe bradycardia and high-grade atrio-ventricular block may be reversed by i.v. atropine sulfate in inferior or posterior acute myocardial infarction (AMI), while in anterior AMI emergency pacing may be required.

Pulmonary oedema. Heart failure during STEMI is associated with poor short- and long-term prognosis, and PPCI is preferred in STEMI complicated by pulmonary oedema. Minor degrees of pulmonary oedema often respond to nitrates and diuretics, and in the absence of hypotension, i.v. nitroglycerine should be administered except in the presence of right ventricular infarction. Oxygen should be administered to patients with breathlessness and/or clinical signs of heart failure and/or cardiogenic shock (CS), and continuous positive airway pressure or endotracheal intubation with ventilatory support may be required. ${ }^{16}$ 
Morphine should be used only when clinically indicated.

Cardiogenic shock. CS complicates AMI in 2.8-11\% of cases, with a median time from AMI onset of 6.2 hours, and a mortality rate $>50 \%$. PPCI is the preferred option in patients with CS and high-risk features, ${ }^{17}$ with TT where PPCI is likely to be delayed. Early diagnosis and treatment of established and developing CS is paramount. Here patients should be transported to PCI- and intra-aortic balloon pump-capable hospitals. Pre-hospital treatment of CS includes volume administration (in the absence of pulmonary oedema), oxygen (to achieve $\mathrm{O}_{2}$ saturation $>95 \%$ ), and inotropic support (dobutamine and dopamine) if the systolic blood pressure is $<90 \mathrm{mmHg}$. In such cases, a low threshold for intubation and mechanical ventilation exists.

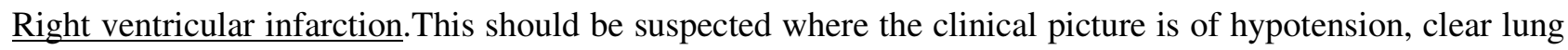
fields and a raised jugular venous pressure in a patient with an inferior STEMI. ST-segment elevation in $V_{4} R$ is also suggestive. Right ventricular preload should be maintained and vasodilators avoided. Although limited fluid expansion is effective in many cases, additional inotropic support may be required. PPCI is the preferred therapeutic option, with TT where PPCI is likely to be delayed.

\section{Education}

The educational challenges for improved pre-hospital care are considerable, ranging from EMS personnel to hospital-based cardiologists, nurses and other paramedical staff, funding bodies, policy makers and planners of health care.

EMS systems vary in their approach to receiving and prioritising emergency calls, ranging from a physician to computerised priority dispatch algorithms. EMS models can be dichotomised as the Franco-German model (physicians in the control room and in ambulances), or the Anglo-American mode (paramedics/emergency medical technician-staffed ambulances, working to agreed protocols, supported by physician direction and/or telemedicine). The duration of training and degree of autonomy varies widely between programmes.

The knowledge, skills and behaviours outlined in the ACS section of the ESC Core Curriculum for the general cardiologist could be expected to apply, in various degrees, to all professionals engaged in prehospital STEMI care. Education of EMS staff in clinical research is of value, to facilitate safe and ethical recruitment to approved, well-designed studies. 


\section{Training}

The need for a medical specialty. Emergency medicine (EM) is the medical specialty with the principal mission of evaluating, managing, treating and preventing unexpected illness and injury. It is a practice in which time is critical. The second EuSEM Core Curriculum for emergency medicine stated a minimum of 5 years in a recognised training program for EM specialists. ${ }^{18}$

The need for a cardiological sub-specialty. Patients admitted to the Intensive Cardiac Care Units (ICCUs) are increasingly older, have more severe cardiac conditions and associated comorbidities, with more than $50 \%$ having important co-morbidities. To deliver optimal treatment to this patient population requires cardiologists to have full knowledge of the range of techniques and procedures required in intensive acute

cardiac care (IACC). ${ }^{19}$ Cardiologists working in ICCUs must therefore adapt their knowledge and abilities to these new demands. The process of certification in IACC should standardise training in the specialty and facilitate delivery of state-of-the-art treatment to patients admitted to ICCUs in Europe. ${ }^{20}$

\section{Summary and conclusions}

The pre-hospital phase is the most critical in STEMI treatment. Minimising patient-related delay is the first key step in STEMI treatment: public/patient education campaigns, community organisation, and the presence of an unique European-wide emergency telephone number may be advisable. The availability of automated external defibrillators (AEDs) in public places may be of value. The ambulance service has a pivotal role in STEMI management and cardiac arrest. All emergency ambulances should be equipped with defibrillators, 12-lead electrocardiographs and staffed with at least one person proficient in advanced cardiac life support. ECG transmission/ teleconsultation may be useful.

Implementation of systems of care has a pivotal role in modern STEMI treatment, based on networks among medical and cardiology institutions of different technological levels, connected by an effective EMS. There are two main models of transfer; the hub-and-spoke transfer system and the STEMI receiving centre (SRC). In the first model, patients presenting to a non-PCI capable hospital are either treated with TT or immediately transferred for PPCI. In the second model, non-SRC are bypassed by transport systems, delivering patients directly to an experienced PPCI centre. An additional option has been proposed with 
experienced interventionalists undertaking PPCI in peripheral catheter laboratories. PPCI is the preferred treatment option for STEMI when performed within guideline times, with the maximal acceptable PPCIrelated delay $<120 \mathrm{~min}$ (<90 $\mathrm{min}$ for young early presenters $)^{7}$. Where PH-T is performed, this results in a reduction of $15-20 \%$ in early mortality, when compared with IH-T, and the combination of PH-T with early (but not immediate) coronary angiography and PCI further improves patients' outcome. Appropriately educated and motivated healthcare professionals are central to overcoming existing barriers to provide optimal patient care. Scientific societies have a critical role in promoting research and guideline implementation, whilst taking into account the the economic imbalances, and diversity of healthcare systems amongst the European countries. ${ }^{5}$ Finally, adequate involvement of political and administrative bodies is mandatory.

Acknowledgements. All the authors listed have contributed significantly to the paper. A two days expert consensus conference was held in Versailles (FR) on 28-29 October 2008. All the authors made a presentation and subsequently provided written documentation in their area of expertise. All the texts were subsequently merged to form a single paper which was reviewed and updated several times by all the authors.

Conflict of interest: Dr. Arntz has received speaker honoraria from Boehringer Ingelheim and Sanofi Aventis and has received support on clinical trials from Boehringer Ingelheim, Sanofi Aventis and Bristol Myers Squibb. Dr. Lettino has received speaker honoraria from AstraZeneca, Eli Lilly, Sanofi Aventis/BMS, Boehringer Ingelheim, Pfizer and Bayer in the past two years. Dr. Lindahl has received research support from Roche Diagnostics and has partecipated in the scientific advisory board of Siemens, Philips and Beckman Coulter Inc.. Dr Price has received speaker honoraria from Medtronic in the past two years. Prof Quinn receives research grants from the UK National Institute from Health Research, National Institute for Health and Clinical Excellence, and advises Boehringer Ingelheim and The Medicines Company on clinical trials regarding acute cardiac care, and has received consultancy fees form BMS, Hoffman La Roche (Canada) and Iroko in the past two years. 


\section{References}

1. Eagle KA, Nallamothu BK, Mehta RH, Granger CB, Steg PG, Van de Werf F, Lopez-Sendon J, Goodman SG, Quill A, Fox KAA for the Global Registry of Acute Coronary Events (GRACE) Investigators. Trends in acute reperfusion therapy for ST-segment elevation myocardial infarction from 1999 to 2006: we are getting better but we have got a long way to go. Eur Heart J 2008;29:609-617.

2. Fox KAA, Huber K. A European perspective on improving acute systems of care in STEMI: we know what to do, but how can we do it? Nat Clin Pract Cardiovasc Med 2008;5:708-714

3. Ting HH, Krumholz HM, Bradley EH, Cone DC, Curtis JP, Drew BJ, Field JM, French WJ, Gibler WB, Goff DC, Jacobs AK, Nallamothu BK, O'Connor RE, Schuur JD. Implementation and integration of prehospital ECGs into systems of care for acute coronary syndrome. A scientific statement from the American Heart Association Interdisciplinary Council on Quality of Care and Outcomes Research, Emergency Cardiovascular Care Committee, Council on Cardiovascular Nursing, and Council on Clinical Cardiology. Circulation 2008;118:1066-1079.

4. Bassand JP, Danchin N, Filippatos G, Gitt A, Hamm C, Silber S, Tubaro M, Weidinger F. Implementation of reperfusion therapy in acute myocardial infarction. A policy statement from the European Society of Cardiology. Eur Heart J 2005;26:2733-2741.

5. Widimski P, Wijns W, Fajadet J, de Belder M, Knot J, Aaberge L, Andrikopoulos G, Baz JA, Betriu A, Claeys M, Danchin N, Djambazov S, Erne P, Hartikainen J, Huber K, Kala P, Klinceva M, Kristensen SD, Ludman P. Mauri Ferre J, Merkely B, Milicic D, Morais J, Noc M, Opolski G, Ostojic M, Radovanovic D, De Servi S, Stenestrand U, Studecan M, Tubaro M, Vasiljevic Z, Weidinger F, Witkowski A, Zeymer U, on behalf of the European Association for Percutaneous Cardiovascular Interventions. Reperfusion therapy for ST elevation acute myocardial infarction in Europe: description of the current situation in 30 countries. Eur 
Heart J 2010;31:943-957.

6. Morrison LJ, Brooks S, Sawadsky B, Mcdonald A, Verbeek PR. Prehospital 12-lead electrocardiography impact on acute myocardial infarction treatment times and mortality: a systematic review. Acad Emerg Med 2006;13:84-89.

7. Van de Werf F, Bax J, Betriu A, Blomstrom-Lundqvist C, Crea F, Falk V, Filippatos G, Fox K, Huber K, Kastrati A, Rosengren A, Steg PG, Tubaro M, Verheugt F, Weidinger F, Weis F. Management of acute myocardial infarction in patients presenting with persistent ST-segment elevation: the Task Force on the Management of ST-Segment Elevation Acute Myocardial Infarction of the European Society of Cardiology. Eur Heart J 2008;29:2909-2945.

8. Morrison L, Verbeek P, McDonald A, Sawadsky B, Cook D. Mortality and prehospital thrombolysis for acute myocardial infarction. A meta-analysis. JAMA 2000;283:2686-2692.

9. Pinto D, Kirtane A, Nallamothu B, Murphy S, Cohen DJ, Laham RJ, Cutlip DE, Bates ER, Frederick PD, Miller DP, Carrozza JP Jr, Antman EM, Cannon CP, Gibson CM. Hospital delays in reperfusion for STelevation myocardial infarction. Implications when selecting a reperfusion strategy. Circulation 2006; 114: 2019-2025.

10. Danchin N, Coste P, Ferrieres J, Steg PG, Cottin Y, Blanchard D, Belle L, Ritz B, Kirkorian G, Angioi M, Sans P, Charbonnier B, Eltchaninoff H, Gueret P, Khalife K, Asseman P, Puel J, Goldstein P, Cambou JP, Simon T, and for the FAST-MI Investigators. Comparison of thrombolysis followed by broad use of percutaneous coronary intervention with primary percutaneous coronary intervention for ST-elevation acute myocardial infarction: data from the French Registry of acute ST-elevation myocardial infarction (FASTMI). Circulation 2008;118:268-276.

11. Kalla K, Christ G, Karnik R, Malzer R, Norman G, Prachar H, Schreiber W, Unger G, Glogar HD, Kaff 
A, Laggner AN, Maurer G, Mlczoch J, Slany J, Weber HS, Huber K and for the Vienna STEMI Registry Group. Implementation of guidelines improves the standard of care: the Viennese registry on reperfusion strategies in ST-elevation myocardial infarction (Vienna STEMI registry). Circulation 2006;113:2398-2405.

12. Saia F, Marozzini C, Ortolani P, Palmerini T, Guastaroba P, Cortesi P, Pavesi PC, Gordini G, Pancaldi LG, Taglieri N, Di Pasquale G, Branzi A, Marzocchi A. Optimization of therapeutic strategies for STelevation acute myocardial infarction: the impact of a territorial network on reperfusion therapy and mortality. Heart 2009;95:370-376.

13. Bøhmer E, Hoffmann P, Abdelnoor M, Arnesen H, Halvorsen S. Efficacy and safety of immediate angioplasty versus ischemia-guided management after thrombolysis in acute myocardial infarction in areas with very long transfer distances: results of the NORDISTEMI (NORwegian study of DIstrict treatment of ST-Elevation Myocardial Infarction). J Am Coll Cardiol 2010;55:102-110.

14. Böttiger B, Arntz HR, Chamberlain D, Bluhmki E, Blemans A, Danays T, Carli PA, Adgey JA, Bode C, Wenzel V, for the TROICA trial investigators and the European Resuscitation Council study group. Thrombolysis during resuscitation for out-of-hospital cardiac arrest. N Eng J Med 2008;359:2651-2662.

15. Dumas F, Cariou A, Manzo-Silberman S, Grimaldi D, Vivien B, Rosencher J, Empana jP, Carli P, Mira JP, Jouven X, Spaulding C. Immediate percutaneous coronary intervention is associated with better survival after out-of-hospital cardiac arrest: insights from the PROCAT (Parisian region out of hospital cardiac arrest) registry. Circ Cardiovasc Interv 2010;doi:10.1161/CIRCINTERVENTIONS.109.913665

16. Wijesinghe M, Perrin K, Ranchard A, Simmonds M, Weatherall M, Beasley R. Routine use of oxygen in the treatment of myocardial infarction: systematic review. Heart 2009;95:198-202.

17. Hochman JS, Sleeper LA, Webb JG, Sanborn TA, White HD, Talley JD, Buller CE, Jacobs AK, Slater JN, Col J, McKinlay SM, LeJemtel TH, for the SHOCK investigators. Early revascularization in acute 
myocardial infarction complicated by cardiogenic shock. N Engl J Med 1999;341:625-634.

18. Petrino R, Ohlen G, Williams D, Sabbe M, Seblova J, Sipria A, Bellou A, Fleischman T, Askitopoulou H, Plunkett P, Spiteri A, van Driel P, Raniszewska E, Arafat R, Vasquez T, Kurland L, Osterwalder J, Durukan P. European curriculum for emergency medicine. http://www.eusem.org/downloads/pdfs/

19. Hasin Y, Danchin N, Filippatos G, Heras M, Janssens U, Leor J, Nahir M, Parkhomenko A, Thygesen K, Tubaro M, Wallentin L, Zakke I, on behalf of the Working Group Acute Cardiac Care of the European Society of Cardiology. Recommendations for the structure, organization and operation of intensive cardiac care units. Eur Heart J 2005;26:1676-1682.

20. Working Group on Acute Cardiac Care, European Society of Cardiology. Core curriculum for training in Intensive and Acute Cardiac Care. http://www.escardio.org/communities/Working-Groups/acute-cardiaccare/Documents/ESC-Curriculum-Training-Intensive-ACC-Europe.pdf 


\section{Legend Figure 1}

Components of total delay to reperfusion in patients with STEMI. Redrawn after Fox \& Huber. ${ }^{2}$

FMC $=$ first medical contact; D2N (door-to-needle) $=$ interval between FMC and the start of fibrinolytic drug administration; D2B (door-to-balloon) = interval between FMC and infarct-related artery (IRA) reopening (by guidewire placement, thrombus aspiration or balloon inflation, whichever comes first). For the other abbreviations, see text. 
Table 1 - European Registries on pre-hospital STEMI care

\begin{tabular}{|c|c|c|c|}
\hline name & country & primary end-point & results \\
\hline $\begin{array}{l}\text { Royal Victoria } \\
\text { Hospital }\end{array}$ & $\begin{array}{l}\text { United } \\
\text { Kingdom }\end{array}$ & PHT vs IHT & $\begin{array}{l}\downarrow \text { call to thrombolysis time } \\
\downarrow \text { mortality }\end{array}$ \\
\hline USIC & France & $\mathrm{PHT}+\mathrm{PCI}$ & $\begin{array}{l}\downarrow \text { mortality with PHT + PCI, in comparison } \\
\text { with IHT, PPCI and non-reperfused pts }\end{array}$ \\
\hline FAST-MI & France & PHT+PCI vs PPCI & comparable results \\
\hline RISK-HIA & Sweden & PHT vs IHT vs PPCI & $\begin{array}{l}\text { PPCI had the lowest mortality, followed by } \\
\text { PHT and then by IHT }\end{array}$ \\
\hline MINAP & $\begin{array}{l}\text { United } \\
\text { Kingdom }\end{array}$ & Reinfarction following PHT & $\begin{array}{l}\text { The lag phase between UFH bolus and start } \\
\text { of infusion is critical for outcome }\end{array}$ \\
\hline Vienna & Austria & $\begin{array}{l}\text { Implementation of a STEMI } \\
\text { city system of care (cath-lab } \\
\text { rotation, PHT) }\end{array}$ & $\begin{array}{l}\text { vs. pre-implementation period: } \\
\uparrow \% \text { reperfused pts } \\
\downarrow \text { mortality }\end{array}$ \\
\hline Bologna & Italy & $\begin{array}{l}\text { Implementation of a STEMI } \\
\text { provincial tiered system of } \\
\text { care (PHT+PCI, PPCI) }\end{array}$ & $\begin{array}{l}\text { vs. pre-implementation period: } \\
\uparrow \% \text { PPCI, } \downarrow \% \text { TT, } \uparrow \% \text { reperfused pts } \\
\downarrow \text { in-hospital and long-term mortality }\end{array}$ \\
\hline NORDISTEMI * & Norway & $\begin{array}{l}\text { TT }(57 \% \text { PHT })+\text { immediate } \\
\text { routine vs later selective } \\
\text { transfer }\end{array}$ & $\downarrow \mathrm{MACE}$ \\
\hline
\end{tabular}

$*$ randomized clinical trial; pts = patients; $\uparrow=$ increase; $\downarrow=$ decrease; for other abbreviations, see text 
Table 2 - Pre-hospital adjuvant antithrombotic therapies

\begin{tabular}{|c|c|c|}
\hline drug & dose & indication \\
\hline aspirin & $\begin{array}{l}150 \mathrm{mg} \text { p.o. }{ }^{*} \\
250-500 \mathrm{mg} \text { e.v.** }\end{array}$ & all STEMI pts \\
\hline clopidogrel & $\begin{array}{l}300 \mathrm{mg} \text { p.o. } \\
600 \mathrm{mg} \text { p.o. } \\
75 \mathrm{mg} \text { p.o. }\end{array}$ & $\begin{array}{l}\text { PPCI and TT in pts } \leq 75 \mathrm{yrs} \\
\text { advisable in PPCI } \\
\text { TT in pts }>75 \mathrm{yrs}\end{array}$ \\
\hline UFH & $\begin{array}{l}100 \mathrm{U} / \mathrm{kg} \text { iv bolus } \\
60 \mathrm{U} / \mathrm{kg}(\max 4000 \mathrm{U}) \text { iv bolus }+12 \mathrm{U} / \mathrm{kg} / \mathrm{h}(\max \\
1000 \mathrm{U} / \mathrm{h}) \text { iv infusion }\end{array}$ & $\begin{array}{l}\text { PPCI } \\
\text { TT and in non reperfusion Rx pts }\end{array}$ \\
\hline enoxaparin & $\begin{array}{l}30 \mathrm{mg} \text { iv bolus }+1 \mathrm{mg} / \mathrm{kg} / 12 \mathrm{~h}(\max 1000 \mathrm{U} / 12 \mathrm{~h}) \\
\text { no bolus }+0.75 \mathrm{mg} / \mathrm{kg} / 12 \mathrm{~h}(\max 75 \mathrm{mg} / 12 \mathrm{~h}) \\
\text { doses every } 24 \mathrm{hrs}\end{array}$ & $\begin{array}{l}\text { TT and in non reperfusion } \mathrm{Rx} \text { pts } \\
\text { TT pts }>75 \mathrm{yrs} \\
\text { pts with } \mathrm{CrCl}<30 \mathrm{ml} / \mathrm{min}\end{array}$ \\
\hline fondaparinux § & $2.5 \mathrm{mg} \mathrm{sc}$ bolus $+2.5 \mathrm{mg} \mathrm{sc} \mathrm{qd}$ & TT and in non reperfusion Rx pts \\
\hline
\end{tabular}




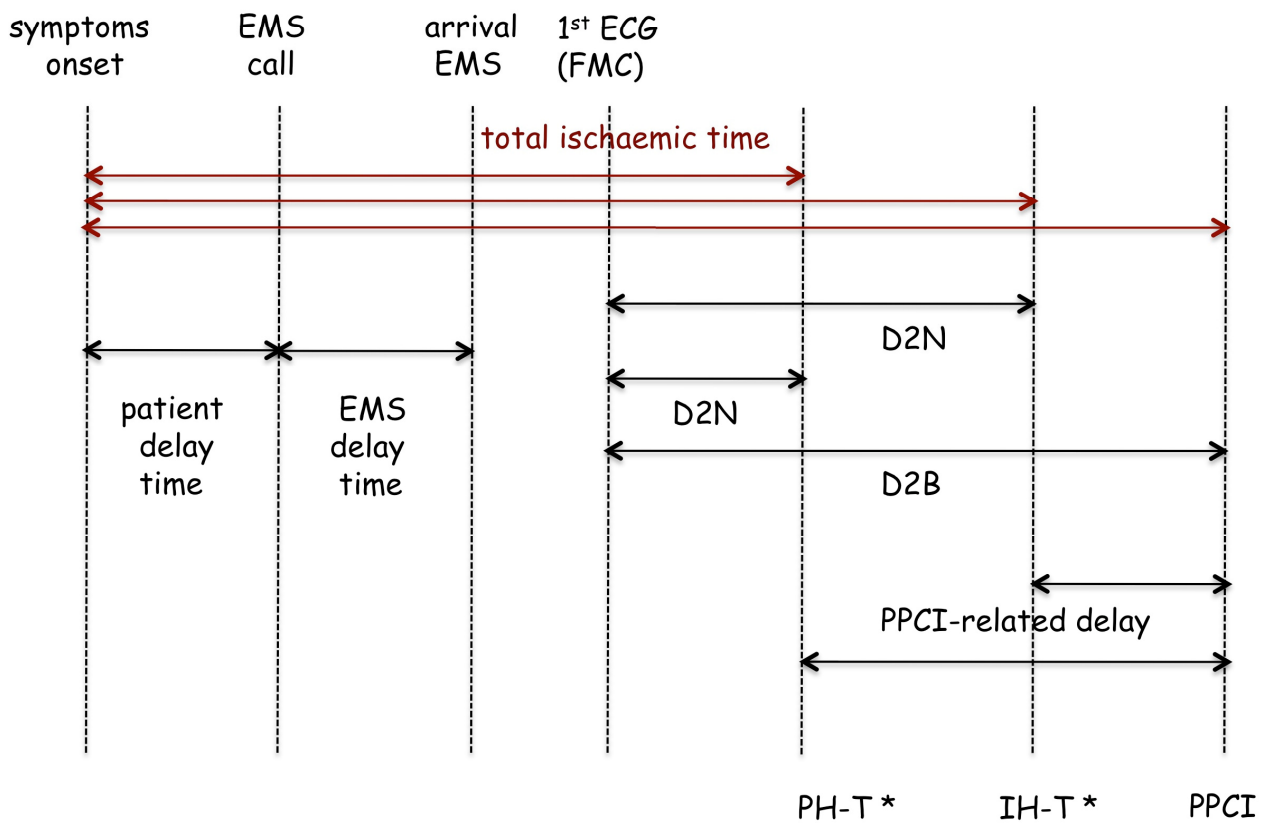

* after delivery of reperfusion therapy, a "reperfusion therapy to coronary recanalization" time should be considered 
Acute coronary syndromes

AED

automated external defibrillator

AMI

acute myocardial infarction

CS

cardiogenic shock

D2B

door-to-balloon time

D2N

door-to-needle time

EM

emergency medicine

EMS

emergency medical service

IACC

intensive acute cardiac care

ICCU

intensive cardiac care unit

$\mathrm{IH}-\mathrm{T}$

in-hospital thrombolysis

MACE

major adverse cardiac events

NSTEMI

non-ST elevation myocardial infarction

PDT

patient's decision time

PH-ECG

pre-hospital electrocardiogram

$\mathrm{PH}-\mathrm{T}$

pre-hospital thrombolysis

$\mathrm{PCl}$

percutaneous coronary intervention

PPCl

primary percutaneous coronary intervention

RCTs

randomised clinical trials

ROSC

return of spontaneous circulation

SRC

STEMI receiving centre

STEMI

ST elevation myocardial infarction

thrombolytic therapy. 